\title{
Rare biliary anatomy in two patients presenting with biliary obstruction diagnosed with ERCP
}

\author{
GARY R MAY, MD, DAVID S REID, MD, NOEL B HERSHFIELD, MD
}

GR MAY, DS REID, NB HERSHFIELD. Rare biliary anatomy in two patients presenting with biliary obstruction diagnosed with ERCP. Can J Gastroenterol 1991;5(5):161-164. Anatomic anomalies of the extrahepatic biliary tree are common and often incidental findings at endoscopic retrograde cholangiopancreatography; however, they rarely complicate therapeutic procedures such as stone extraction. The cases of two patients with biliary obstruction due to stones are presented, who were found to have the cystic duct arising almost directly from the ampulla. This rare anatomic variant posed problems both in terms of interpretation of the cholangiogram and removal of stones. Therapeutic endoscopists should be aware of this and other anomalies of the biliary tract and of the potential problems faced in both interpretation of the cholangiogram and in therapeutic procedures.

Key Words: Anomalies, Bile ducts, Biliary obstruction, Endoscopy, ERCP

Rare anomalie congénitale des voies biliaires découverte lors d'une cholangio-pancréatographie rétrograde endoscopique chez deux patients souffrant d'obstruction biliaire

RESUME: Les anomalies congénitales des voies biliaires extrahépatiques sont courantes et souvent révélées par la cholangio-pancréatographie rétrograde endoscopique; elles gênent toutefois rarement le traitement - l'extraction des calculs, notamment. Le présent article présente le cas de deux patients atteints d'obstruction biliaire lithiasique et chez qui on a découvert que le canal cystique débouchait presque directement de l'ampoule. Cette variante anatomique rare compliquait l'interprétation du cholangiogramme et l'extraction des calculs. Les endoscopistes thérapeutiques devraient être conscients des diverses anomalies des canaux biliaires et des problèmes qu'elles peuvent créer pour l'interprétation du cholangiogramme et la thérapeutique.

Departments of Gastroenterology and Radiology, Foothills Hospital and the University of Calgary, Calgary, Alberta

Correspondence and reprints: Dr NB Hershfield, \#711 South Tower, 3031 Hospital Drive NW, Calgary, Alberta T2N 2T8

Received for publication April 29, 1991. Accepted July 30, 1991
A NOMALIES OF THE EXTRAHEPATIC biliary tree are relatively common (1). It is of great importance that they be recognized by the surgeon at the time of cholecystectomy to avoid damage to the biliary tree; however, they are usually incidental findings at endoscopic retrograde cholangiopancreatography (ERCP) and rarely complicate therapeutic endoscopic procedures. The insertion of the cystic duct into the common hepatic duct is variable, with anomalous insertion seen in greater than 25\%. In approximately $10 \%$ of cases the cystic duct spirals around the common hepatic duct to insert on the left side (2). Insertion can occur at any level along the common hepatic duct, although insertion at the ampulla is said to be rare and has been infrequently reported in the literature (3). The authors report the cases of two patients presenting with biliary obstruction who were found to have this rare anatomic variant at ERCP.

\section{CASE ONE}

An 83-year-old male with a history of chronic atrial fibrillation presented to emergency following a collapse at home. On initial evaluation the patient was found to be febrile $\left(38.3^{\circ} \mathrm{C}\right)$ with scleral icterus. Laboratory data were 
unremarkable apart from an aspartate aminotransferase of $162 \mathrm{U} / \mathrm{L}$ (normal 0 to 41 ), an alkaline phosphatase of 431 $\mathrm{U} / \mathrm{L}$ (normal 30 to 115 ) and a bilirubin of $59 \mu \mathrm{mol} / \mathrm{L}$ (normal 3 to 20 ). No cardiac or neurological cause could be found for the collapse. Blood cultures were negative. An abdominal ultrasound showed dilation of both the intra- and extrahepatic bile ducts, with echogenic material present within the distal common bile duct.

ERCP was performed using an Olympus JF-1T20 duodenoscope using fentanyl and diazepam for sedation. On the initial cholangiogram it was unclear if the common bile duct was completely obstructed or if it was an anomalous cystic duct (Figure 1). After repositioning of the cannula, the common hepatic and intrahepatic ducts filled, showing the cystic duct arising almost directly from the ampulla (Figure 2). The pancreatic duct was normal. Multiple stones were present within both ducts. Following sphincterotomy, a balloon catheter was inserted separately into the cystic and common hepatic ducts and the stones extracted from the respective ducts. The patient had rapid resolution of his jaundice and biochemical abnormalities and is doing well after four months of follow-up.

\section{CASE TWO}

A 76-year-old Caucasian female with a history of cholecystectomy 15 years earlier presented with a two month history of episodic right upper quadrant abdominal pain associated with nausea and vomiting. Physical examination was unremarkable. Laboratory data were within normal limits except for an aspartate aminotransferase of $69 \mathrm{U} / \mathrm{L}$, an alkaline phosphatase of $165 \mathrm{U} / \mathrm{L}$ and a bilirubin of 16 $\mu \mathrm{mol} / \mathrm{L}$. An ultrasound showed a dilated extrahepatic biliary tree.

ERCP was performed using an Olympus JF-1T20 duodenoscope following sedation with fentanyl and diazepam. A stone was found in the ampullary segment. This was extracted following sphincterotomy. A second stone was present at the junction of the cystic and common hepatic ducts. This

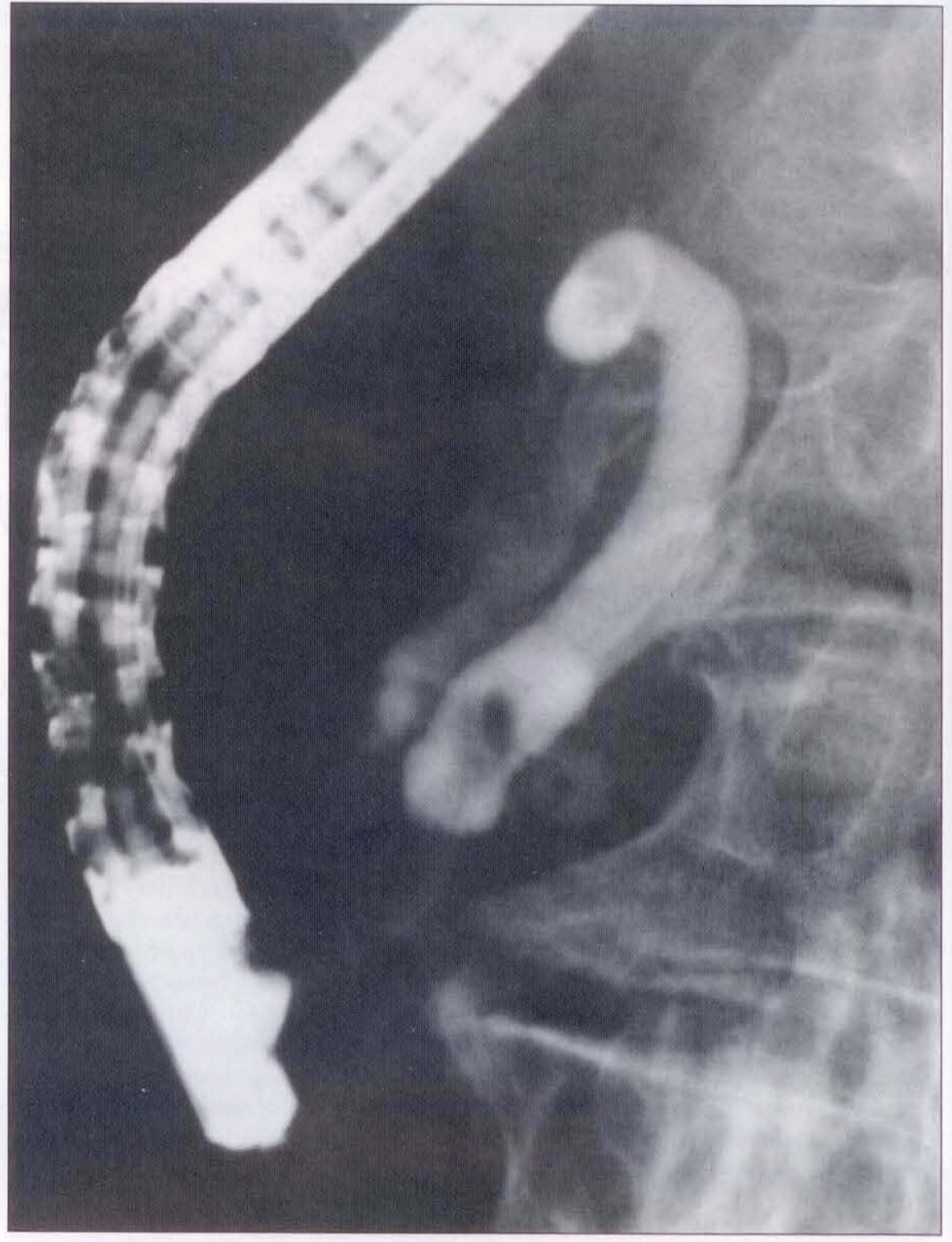

Figure 1) Initial retrograde cholangiogram from patient 1 , showing predominant filling of the cystic duct. The gallbladder does not fill and there is a stone present within the distal cystic duct

junction was very low, just above the ampulla, giving a very short common bile duct segment. Attempts at extraction of the second stone with a balloon catheter were unsuccessful. The catheter would preferentially enter the cystic duct due to the angle at which the common hepatic and cystic ducts joined. As the stone was not obstructing it was left in place and the patient was discharged. She returned three weeks later, at which time a repeat ERCP showed that the stone had passed, and the authors were able to obtain lateral films which defined the anatomy, showing a low spiral junction of the common hepatic and cystic ducts, giving a very short common bile duct (Figure 3).

\section{DISCUSSION}

Anomalies of the extrahepatic biliary tree have long been recognized to be both frequent and variable (4). The frequency of these anomalies tends to vary depending on the method used to detect them (dissection versus radiography), material studied (cadaveric versus operative specimens), and between series. The significance of these anomalies is predominantly surgical in that it is important that they be recog. nized at the time of cholecystectomy to avoid inadvertent injury to the biliary 


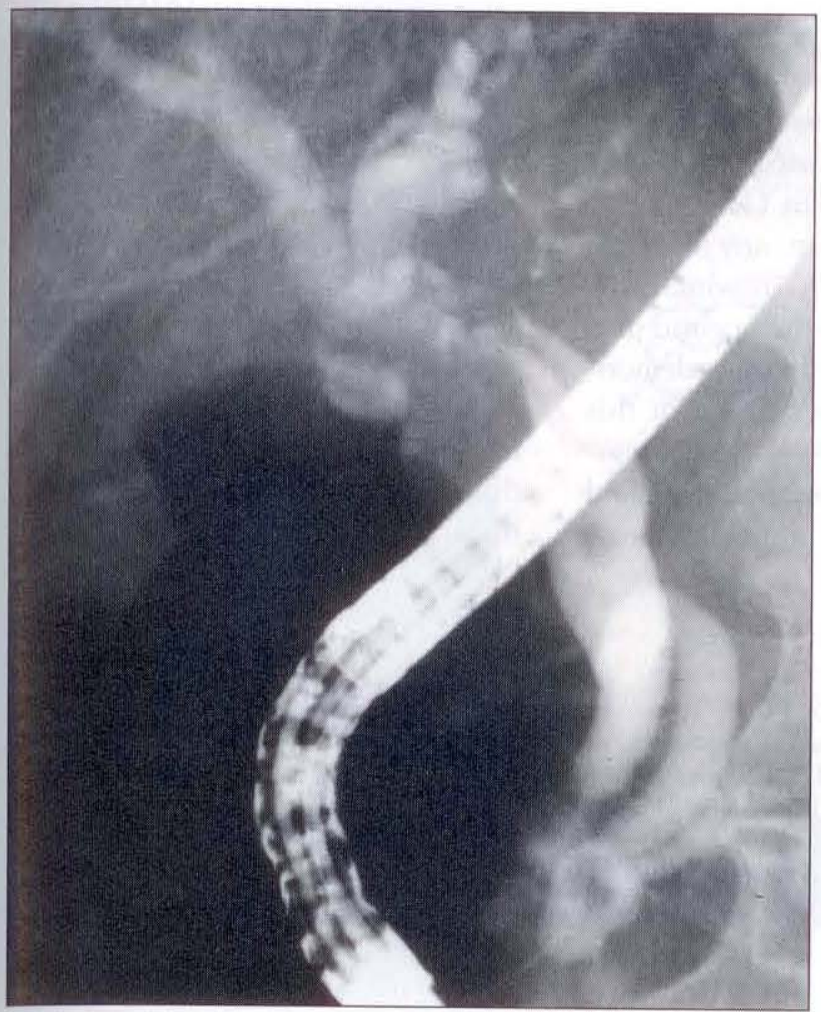

Figure 2) Retrograde cholangiogram from patient I following partial filling of the common hepatic duct. The common hepatic and cystic ducts arise separately from the ampulla. Stones are present within the distal cystic duct and mid common hepatic duct. The pancreatic duct was normal (entire duct not shown)

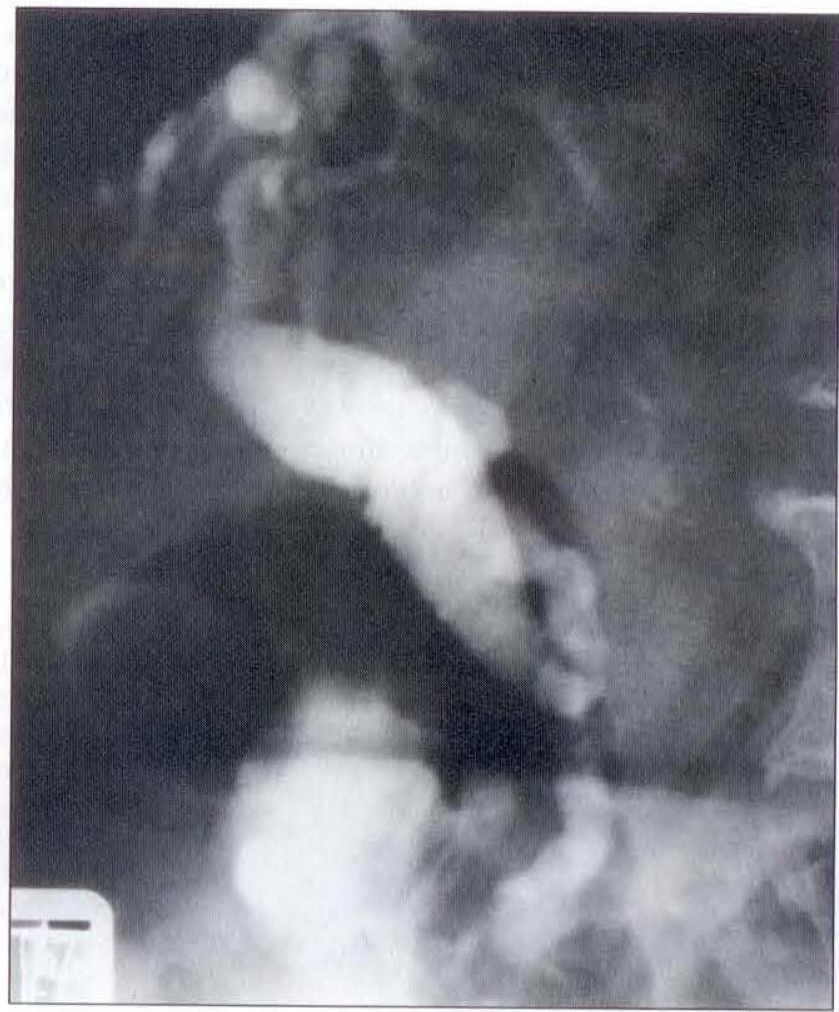

Figure 3) Retrograde cholangiogram from patient 2 showing a low spiral junction of the cystic and common hepatic ducts within $3 \mathrm{~cm}$ of the ampulla. No residual stone was visualized tree and postoperative complications (5). For the endoscopist, these anomalies are often found at the time of ERCP, and except for anomalies that involve the anatomy of the papilla (making identification and cannulation difficult), they rarely complicate ERCP or therapeutic procedures.

The junction of the cystic duct with the common hepatic duct shows great variability, with the 'normal' angular entry of the cystic duct into the common hepatic duct seen in only 53 to $65 \%$ of cases $(2,4,6)$. In approximately $25 \%$ it will run a parallel course for a variable length to enter the common hepatic duct from the right. In 10\% it takes a spiral course to enter the common hepatic duct on the left side (3). In the latter situation, the site of entry can be anywhere along the common hepatic duct, from the bifurcation to the duodenal papilla. Other series report the frequency of a spiral cystic duct insertion as high as 35\% with a low parallel insertion seen in 7\% (6). Termination of the cystic duct at the papilla is said to be rare (3). The frequency of having the cystic duct enter the common hepatic duct at the ampulla, designated "les cholédoques courts" or 'short bile duct' by Salembier (7), is difficult to determine from the existing literature since this anatomy is usually not differentiated from a low spiral or parallel insertion with a variable length of common bile duct present. Johnston (1) defines a low parallel insertion of the cystic duct as a parallel segment greater than $4 \mathrm{~cm}$ in length. In his series this occurred in only $2.9 \%$.

In a series reported by Heloury et al (8), the biliary anatomy was reviewed in 250 intraoperative cholangiograms. In $80 \%$ the cystic duct terminated on the right side of the common hepatic duct. In only $2 \%$ was the termination of the cystic duct said to be near the papilla, although this was not clearly defined.

The pathogenesis of this anomaly is not clear. Normally the cystic duct and gallbladder develop from the small caudal division of the hepatic diver- ticulum during the fourth to sixth weeks of embryogenesis. It attaches to the ventral aspect of the duodenum and rotates along with the ventral pancreatic bud to the dorsal aspect of the duodenum by the eighth week (9). Presumably, anomalies of cystic duct anatomy could result from variations either in the development of the caudal part of the hepatic diverticulum or during rotation from the ventral to dorsal aspect of the duodenum.

There are only a few case reports of this anatomy diagnosed by ERCP. Watanabe et al (10) reported the case of a patient with a choledochoduodenal fistula and a long cystic duct draining into the papilla. This patient presented with abdominal pain which resolved spontaneously and has not required any further investigation or therapy (10). Presumably there was a stone impacted in the ampulla which eroded into the duodenum. A preliminary report of a second case of a long cystic duct draining directly into the papilla diagnosed with ERCP was 
reported by Iwamoto et al (11). This patient had other anomalies of the biliary tree including a diverticulum of the gallbladder (11). A third case was recently reported of a 26-year-old female who presented with abdominal pain and jaundice. Using combined percutaneous transhepatic cholangiography and ERCP this patient was shown to have a dilated cystic duct with a low insertion into the common hepatic duct, as well as an anomalous junction of the common bile duct and

\section{REFERENCES}

1. Johnston EV, Anson BJ. Variations in the formation and vascular relationships of the ducts. Surg Gynecol Obstet 1952;94:669-86.

2. Hand BH. Anatomy and embryology of the biliary tract and pancreas. In: Sivak MV Jr, ed. Gastroenterologic Endoscopy. Philadelphia: WB Saunders, 1987:599-618.

3. Hand $\mathrm{BH}$. Anatomy and function of the extrahepatic biliary system. Clin Gastroenterol 1973;2:3-29.

4. Hayes MA, Goldenberg IA, Bishop CC. The developmental basis for bile duct anomalies. Surg Gynecol Obstet 1958; 107:447-56.

5. Benson EA, Page RE. A practical pancreatic duct giving a long common channel. No stone was demonstrated, and the patient was treated with surgical excision of the dilated cystic duct and hepaticojejunostomy (12).

There has not been any case reported in the literature in which this anatomy complicated therapeutic procedures. The present two cases demonstrate the potential problems that this anatomic variant may pose in both interpretation of the cholangiogram and stone extraction. This anomaly appears

reappraisal of the anatomy of the extrahepatic bile ducts and arteries. Br J Surg 1976;63:853-60.

6. Hamlin JA. Biliary ductal anomalies. In: Berci G, Hamlin JA, eds. Operative Biliary Radiology. Baltimore: Williams and Wilkins, 1981:109-35.

7. Salembier Y. Les choledoques 'courts'. Nouv Presse Med 1977;6:2677-984.

8. Heloury Y, Leborgne J, Rogez JM, et al. Radiological anatomy of the bile ducts based on intraoperative investigation . in 250 cases. Anat Clin 1985;7:93-102.

9. Moore KL. The Developing Human. Clinically Oriented Embryology, 4th edn. Toronto: WB Saunders, 1988:223-5.

10. Watanabe A, Ohashi Y, Nagashima H. to be uncommon, with an estimated frequency in the existing literature of approximately $2 \%$.

It is important to be aware of such anomalies of cystic duct anatomy to avoid misinterpretation of the initial cholangiograms. Therapeutic procedures such as stone extraction and the placement of stents may also be complicated since it may be difficult to access the proximal biliary tree depending on the angle of junction between the cystic and common hepatic ducts.

Anomalies of the bile ducts: A case report of direct drain of the cystic duct into the papilla of Vater. Acta Med Okayama 1983;37:409-15.

11. Iwamoto T, Fujii T, Ikeda A, Tanaka M, Nakagama F, Iwata A. Anomalies of the biliary tract. A case with direct drain of the cystic duct proved preoperatively by endoscopic retrograde pancreatico-

cholangiography. Jpn J Gastroenterol 1990;77:1507. (Abst)

12. Kise Y, Uetsuji S, Takada H, Yamamura M, Yamamoto M. Dilatation of the cystic duct with its congenital low entry into the common hepatic duct. Am J Gastroenterol 1990;85:769-70. 


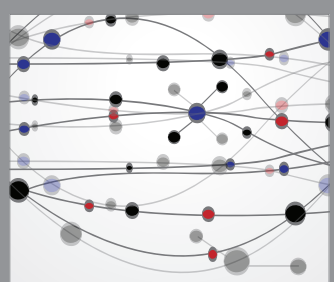

The Scientific World Journal
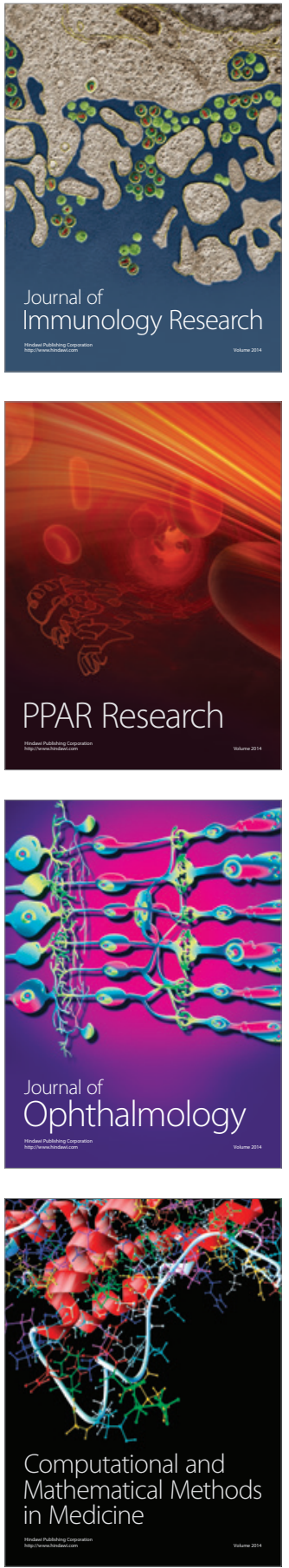

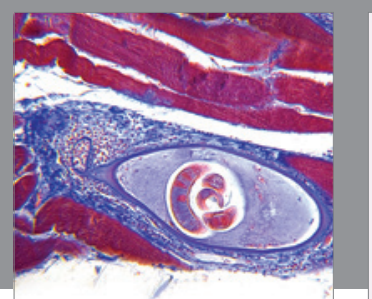

Gastroenterology Research and Practice

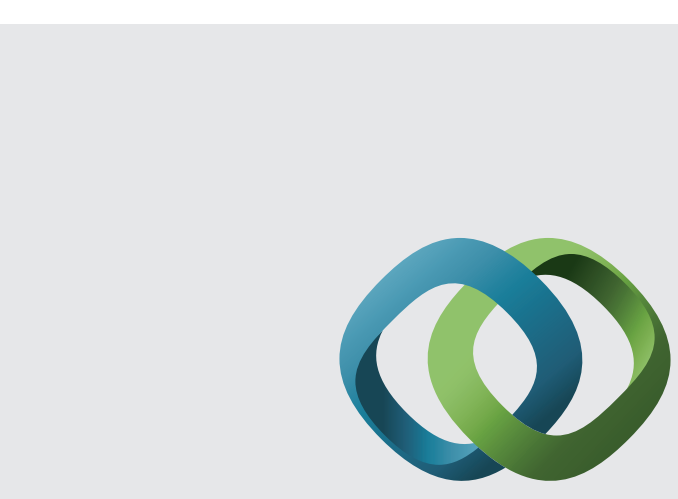

\section{Hindawi}

Submit your manuscripts at

http://www.hindawi.com
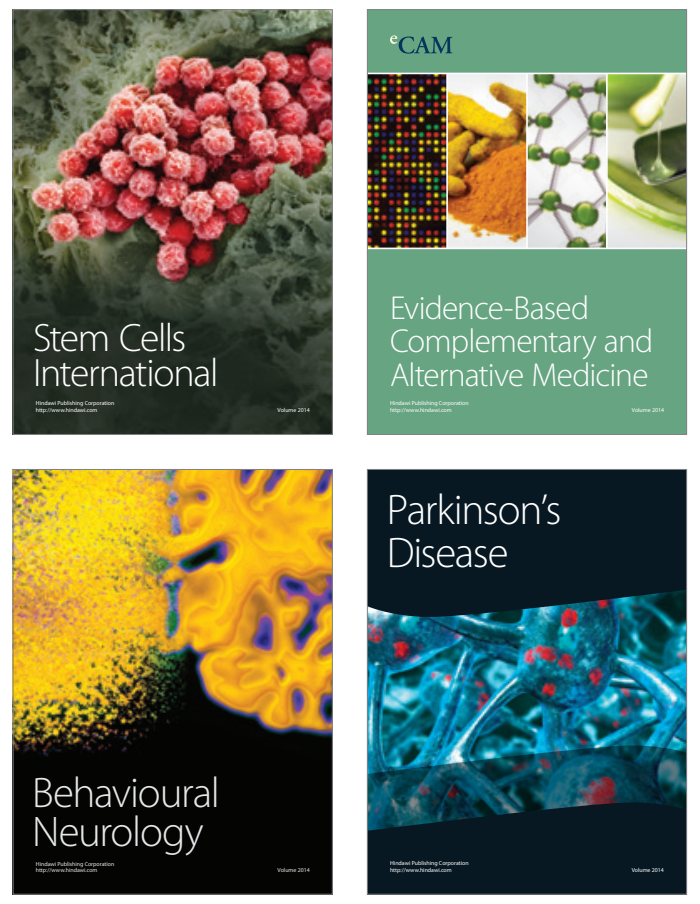
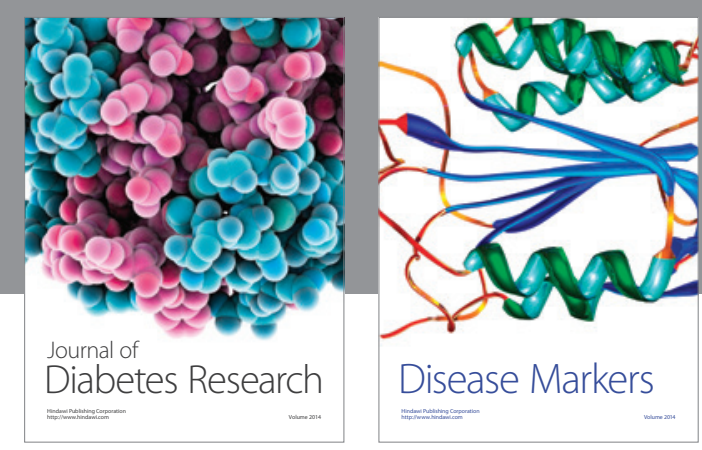

Disease Markers
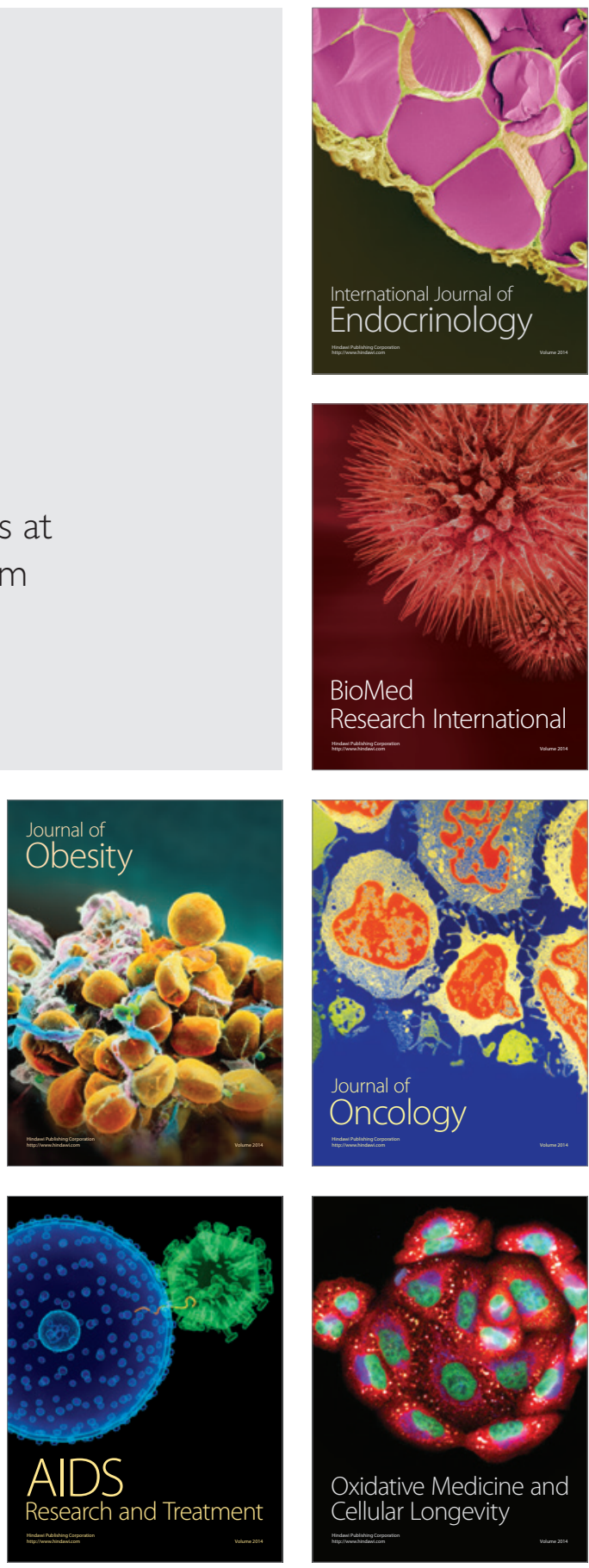